\title{
The Cassel saved
}

\section{Rosalind Ramsay, Registrar in Psychiatry, University College and Middlesex School of Medicine, London W1N 8AA}

In-patient psychotherapy at the Cassel Hospital will continue at least for the time being. Early last year, however, its future was in doubt. In January, the managing health authority, Riverside, faced an annual spending deficit of $£ 6.7$ million. The hospital costs $£ 1.25$ million to run each year; in February, district management recommended closure of the 70 year old Cassel as the top item on their proposed shortlist of economy measures.

Proponents of the closure measure argued that the Cassel was an expensive, highly specialised but dispensable unit taking into treatment a select group of just 80 in-patients each year. As the District General Manager Mr David Knowles pointed out, in no other part of the country is there a comparable service available; he believed that provided some part of the out-patient work continued, Riverside would still be in a position to provide adequate psychotherapy facilities for its residents.

However, hospital staff argued that its sources should be maintained intact as otherwise a group of chronic, highly disabled patients would be unable to obtain effective treatment anywhere in the NHS. Although the number of such patients in any one district is small, overall their numbers are large; such patients make inordinate and expensive demands on local services. It is hardly surprising that no more than $20 \%$ of in-patients at the Cassel come from Riverside.
The hospital accepts severely disturbed neurotic individuals and sometimes whole families for treatment as both in-patients and out-patients. Those patients admitted to the Cassel have regular individual psychotherapy sessions with experienced therapists who are themselves supervised by a senior analyst. Some also attend twice weekly psychoanalytical groups. Drugs, however, are almost never used. In general, patients are expected to participate in activities of all kinds: to stick to the timetable, especially for getting up and going to bed; to come to meals; and to work at given tasks such as cleaning and caring for their own parts of the hospital and helping in the planning and cooking of meals in the evenings and at weekends. According to John Denford, a consultant psychotherapist at the Cassel for the last 14 years, admission to hospital facilitates communication skills in patients. Living together enables the development of many potentially therapeutic relationships both with other patients and with staff. The combination of social therapy and psychotherapy is a powerful instrument challenging people to change yet able to hold them at the same time. Although this treatment approach requires considerable therapist in-put in the short-term, it is effective in $70-80 \%$ of cases in the long-term.

In addition, the hospital is an important teaching centre. About a fifth of the consultant psycho-

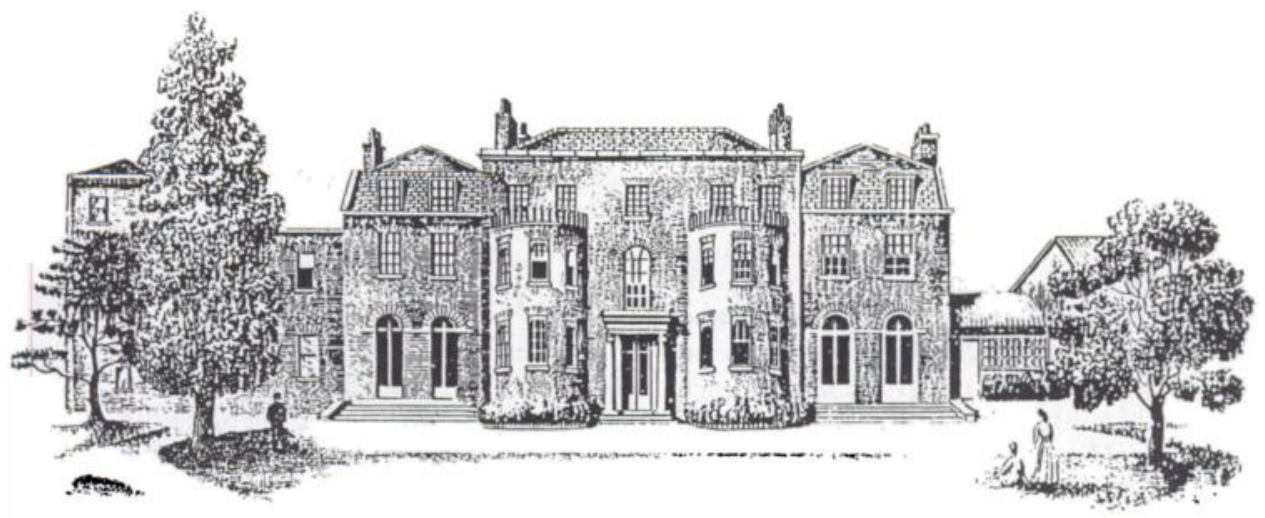

The Cassel Hospital 
therapists working in this country trained there. It also runs a unique course in psychosocial nursing.

Plans to shut the Cassel announced at the start of 1990 were widely criticised. At the health authority's meeting in February, district manager Mr Knowles while proposing closure, at the same time suggested a scheme for fund raising and preparing a business plan that would ensure the Cassel's safety until April 1991, when it would be able to test itself out in the new conditions of the NHS 'open market'. A three month consultation period began. The hospital received the services of a financial manager to help in preparing a package to raise $£ 300,000$ within the year and draw up a business plan for use in the internal market from next April.

During the consultation period the hospital was widely supported by former patients, the media, poli- ticians, the general public and other colleagues. As a result, the district health authority withdrew their closure proposals in June, although the need to raise $£ 300,000$, the hospital's share of cuts applied across Riverside remains. Any shortfall in fund raising by April 1991 will become a charge on the hospital's operating costs, and may eventually lead to equivalent cuts in the service as originally put forward in February. Fund-raising measures are likely to include soliciting donations and perhaps a public appeal, properly costed training and consultations and a small number of private patients, up to $10 \%$ of in and out-patients. The Cassel must change but its survival has once more been guaranteed.

See Correspondence, p. 40.

\title{
Non attenders at a marital and sexual difficulties clinic
}

\author{
R. Huws, Senior Registrar in Psychiatry, Marital and Sexual Difficulties Clinic, \\ Whitely Wood Clinic, Woofinden Road, Sheffield S10 3TL
}

The Marital and Sexual Difficulties Clinic at Sheffield offers out-patient treatment that is usually based on a modified Masters \& Johnson method. This consists of behavioural techniques, notably sensate focus, used within a psychoanalytic background.

A study of 339 clients referred to a sexual dysfunction clinic (Forday-Settlage, 1975), found a $41 \%$ nonattendance rate for the first appointment. Bancroft \& Coles (1976) looked at 275 referrals to the sexual problem clinic at Oxford in the three years up to 1975 . Of these, $75(27 \%)$ did not attend the first appointment. Neither study compared the characteristics of attenders with non-attenders.

Hillis \& Alexander (1990) compared 129 nonattenders to a psychiatric clinic with 100 attenders. Sociodemographic factors did not play a significant part in non-attendance. Patients were more likely to attend if they received a letter rather than a standard appointment card $(P<0.05)$, if they had a previous psychiatric history $(P<0.05)$ or if the appointment was at a mental health centre rather than at a psychiatric hospital $(P<0.02)$. Other studies suggest that absences are due to an interaction of demographic variables, presenting problem and treatment variables. Swenson \& Pekarik (1988) aimed to reduce non-attendance at an initial interview at a community mental health centre by the use of letter prompts. They found that intervention by letter was a successful and practical way to decrease nonattendance. For the health centre, the intervention was cost effective, but as Swenson \& Pekarik point out, for a service with a lower rate of non-attendance this would not necessarily be the case. It might therefore be more useful to target intervention towards certain groups.

The present study examines the demographic characteristics of attenders and non attenders at the Marital and Sexual Difficulties Clinic with the aim of determining if it is possible to target key groups for intervention.

\section{Findings}

The referrals for one year were examined. Out of 269 referrals, 145 attended (54\%). Often the referral letters did not give a clear picture of the problem. In $81 \%$ of the male referrals the problem stated was impotence and in $83 \%$ of the female referrals the problem was lack of interest in sex. There was no difference between attenders and non attenders in 